tôi cũng khá tương đồng với M.N.Chowta và cộng sự. ${ }^{4}$ Trong nghiên cứu của chúng tôi, nồng độ $\mathrm{C}$ - Peptide lúc đói ở nhóm bệnh nhân có MAU và không có MAU lần lượt là: $0,72 \pm 0,34$ $\mathrm{nmol} / \mathrm{l}$ và $0,88 \pm 0,35 \mathrm{nmol} / \mathrm{l}$. Sự khác biệt có ý nghĩa thống kê với $p<0,05$ ( $p=0,047$, Mann Whitney U Test). Ngoài ra chúng tôi cũng nhận thấy có sự tương quan nghịch biến mức độ vừa phải giữa nồng độ $C$ - Peptide lúc đói với nồng độ albumin niệu (Spearman Test, $r=-0,352, p=$ $0,001)$. Kết quả này cũng tương tự với nghiên cứu của Maimoona Mushtaq Masoom và công sự ${ }^{5}$ cũng như'S. Bo và cộng sự. . Cơ chế về $C-$ Peptide tác động đến chức năng thận vẫn còn chưa được làm rõ. Tuy nhiên có thể C - Peptide có ảnh hưởng đến việc giảm albumin niệu, dựa trên nghiên cứu của Mats Sjoquist và cộng sự thí nghiệm trên chuột. ${ }^{7}$ Cũng trong nghiên cứu của chúng tôi, nồng độ $C$ - Peptide lúc đói trên nhóm bệnh nhân có $B V M Đ T Đ$ và không có $B V M Đ T Đ$ lần Iượt là: $0,72 \pm 0,33 \mathrm{nmol} / \mathrm{lvà} 0,9 \pm 0,36 \mathrm{nmol} / \mathrm{l}$. Sự khác biệt này có ý nghĩa thống kê với $\mathrm{p}<$ 0,05 ( $p=0,041$, Mann - Whitney U Test). Điều này phù hợp với nhận xét của S.Bo và cộng sự̆.

\section{KẾT LUÂN}

- Nồng độ $C$ - Peptide lúc đói trên nhóm bệnh nhân nghiên cứu là $0,83 \pm 0,35 \mathrm{nmol} / \mathrm{l}$.

- Có mối tương quan nghịch biến mức độ vừa phải giữa nồng độ $\mathrm{C}-$ Peptide lúc đói với nồng độ Albumin niệu. Nhóm bệnh nhân có MAU có nồng độ $\mathrm{C}$ - Peptide thấp hơn so với nhóm bệnh nhân không có MAU. Sự khác biệt có ý nghĩa thống kê.

- Nồng độ $C$ - Peptide lúc đói giảm liên quan có ý nghĩa tới BVMĐTĐ.

\section{TÀI LIÊU THAM KHẢO}

1. Gross JL, de Azevedo MJ, Silveiro SP, Canani LH, Caramori ML, Zelmanovitz T. Diabetic nephropathy: diagnosis, prevention, and treatment. Diabetes Care. 2005;28(1):164-176. doi:10.2337/diacare.28.1.164

2. Ahmad $T$, Ulhaq $I$, Mawani $M$, Islam $N$. Microalbuminuria in Type-2 Diabetes Mellitus; the tip of iceberg of diabetic complications. Pak J Med Sci. 2017;33(3):519-523. doi:10.12669/ pjms.333.12537

3. Yau JWY, Rogers SL, Kawasaki R, et al. Global prevalence and major risk factors of diabetic retinopathy. Diabetes Care. 2012;35(3):556-564. doi:10.2337/dc11-1909

4. Chowta MN, Adhikari PM, Chowta NK Shenoy AK, D'Souza S. Serum C peptide level and renal function in diabetes mellitus. Indian J Nephrol. 2010;20(1):25-28. doi:10.4103/09714065.62093

5. Masoom MM, Albiladi F. C-Peptide as a Marker for Diabetic Nephropathy. Intern Med Open Access. 2017; 07(03). doi:10.4172/2165-8048. 1000245

6. Bo $S$, Cavallo-Perin $P$, Gentile $L$, Repetti $E$, Pagano G. Relationship of residual beta-cell function, metabolic control and chronic complications in type 2 diabetes mellitus. Acta Diabetol. 2000;37(3):125-129. doi:10.1007/s005920070014

7. Sjöquist $M$, Huang $\mathbf{W}$, Johansson BL. Effects of C-peptide on renal function at the early stage of experimental diabetes. Kidney Int. 1998; 54(3): 758-764. doi:10.1046/j.1523-1755.1998.00074.x

\title{
SO SÁNH CÁC PHƯƠNG PHÁP KIỂM TRA DELTA CHO MộT SỐ XÉT NGHIÊM HÓA SINH
}

\section{TÓM TĂT}

Kiểm tra delta (Delta check) là phương pháp kiểm soát chất lượng so sánh kết quả xét nghiệm hiện tai và kết quả trước đây của cùng môt bệnh nhân phát hiện xem sự khác biệt giữa hai kết quả có vượt quá các tiêu chí được xác đinh trước hay không. Kiểm tra delta đảm bảo phát hiện các lỗi giai đoan trước xét nghiệm, lỗi sao chép và lỗi ngẫu nhiên khống thể phát

${ }^{1}$ Trường Đại học Y Hà Nội

${ }^{2}$ Bênh viên Thanh Nhàn Hà Nôi

Chịu trách nhiệm chính: Nguyễn Thị Tùy Châu

Email: anhchau2016hs@gmail.com

Ngày nhận bài: 22.6.2021

Ngày phản biên khoa hoc: 16.8.2021

Ngày duyệt bài: 24.8.2021

\section{Trần Thị Chi Mai ${ }^{1}$, Nguyễn Thị Tùy Châu $^{2}$}

hiên được bằng các phương pháp kiểm soát chất lượng thường được sử dụng, do đó cải thiện độ tin cậy của các xét nghiệm. Nghiên cứu được tiến hành nhằm so sánh phân bố số liệu của khác biệt delta và thay đổi phần trăm delta chó một số xét nghiếm hoá sinh trên bệnh nhân nội trú và ngoại trú. Thu thập các căp kết quả xét nghiệm của bệnh nhân được tiến hành trên cùng một máy hóa sinh tự động. Phân bố khác biệt delta ở các mức phân vị trền bềnh nhân nội trú của xét nghiệm Glucose, AST, ALT, Natri, Kali, Clo, Canxi lớn hơn so với trên bệnh nhân ngoại trú. Với xét nghiệm Urê và Creatinin, phân bố khác biệt delta trên bệnh nhân nội và ngoại trú có xu hướng tương tự nhau. Khi so sánh với bênh nhân nôi trú, phân vị thứ $50,95,97.5$ và 99 của thay đổi phần trăm delta của các xét nghiêm urê, creatinin, glucose, canxi trên bệnh nhân ngoại trú nhỏ hơn; trong khi AST, ALT, 
Natri, Kali, Clo lại có xu hướng ngược lại. Kết quả này cho thấy việc phân chia bệnh nhân thành nhóm nội trú và ngoại trú là thích hợp để xác định các ngưỡng kiểm tra delta phù hợp cho mối đối tượng này.

Tư khóa: Kiểm tra delta, khác biệt delta, thay đổi phần trăm delta, bệnh nhân nội trú, bệnh nhân ngoại trú.

\section{SUMMARY \\ DELTA CHECKS COMPARED FOR SELECTED BIOCHEMISTRY TESTS}

Delta check is a quality control method that compares current and previous test results of patients and detects whether the difference between the two results exceeds pre-defined criteria. Delta check methods ensure the detection of pre-analytical errors, clerial errors, and random errors that cannot be detected using commonly used quality control methods, thereby improving the reliability of clinical tests. The study was conducted to compare the distribution of delta difference and delta percent change for several biochemical tests in inpatients and outpatients. The paired of patient test results obtained on the same automated biochemistry analyser for 9 clinical chemistry tests were collected from inpatients and outpatients. The distribution of delta difference of glucose, AST, ALT, sodium, potassium, chloride, calcium tests at several percentiles in inpatients was larger than in outpatients. For urea and creatinine tests, the distribution of delta differences in inpatients and outpatients tended to be similar. When compared with inpatients, the 50th, 95th, 97.5th, and 99th percentiles of the delta percent change of the urea, creatinine, glucose, calcium tests in the outpatients were smaller; while AST, ALT, sodium,potassium, chloride tended to be larger. This result suggests that it is needed to divide patients into inpatient and outpatient groups to determine appropriate delta check thresholds for each of these subjects.

Keywords: Delta check, delta difference, delta percent change, inpatient, outpatient.

\section{I. ĐĂT VẤN ĐỀ}

Theo dõi sư thay đổi trên lâm sàng ở bênh nhân là một lý do phổ biến để chỉ định các xét nghiệm. Những thay đổi trong kết quả xét nghiểm ở các mẫu liên tiếp trên cùng bênh nhân có thể xảy ra do nhiều yếu tố khác nhau: giai đoạn trước xét nghiệm, xét nghiệm, sau xét nghiệm, biến thiên sinh học, các yếu tố sinh lý bệnh và sai số. Bên cạnh kiểm tra chất lượng xét nghiệm, nhu cầu về các quy trình đảm bảo chất lượng khác phát sinh do sai sót xảy ra nhiều nhất ở giai đoạn trước xét nghiệm[1], gần $50 \%$ trong số này có liên quan đến thu thập mẫu và lỗi ghi nhãn [2]. Kiểm tra Delta (Delta check) là phương pháp kiểm soát chất lượng so sánh kết quả xét nghiệm hiện tại và kết quả trước đây của cùng một bênh nhân phát hiện xem sự khác biệt giữa hai kểt quả có vượt quá các tiêu chí được xác định trước hay không. Nếu chênh lệch nhỏ hơn tiêu chí được xác định trước, kết quả sẽ được báo cáo tự động; tuy nhiên nếu sự khác biệt vượt quá các tiêu chí được xác định trước, kết quả chỉ được trả sau khi nhân viên phòng xét nghiệm xem xét và xác nhận thủ công[3],[4]. Kiểm tra Delta đảm bảo phát hiện các lối giai đoạn trước xét nghiệm, lỗi sao chép và lỗi ngẫu nhiên không thể phát hiện được bằng các phương pháp kiểm soát chất lượng thường được sử dung, do đó cải thiện độ tin cậy của các xét nghiệm lâm sàng [5],[6]. Tuy nhiên việc sử dụng quá mức hoặc không phù hợp các phương pháp kiểm tra delta có thể làm chậm thời gian trả kết quả và tăng khối lượng công việc do cần phải xác nhận thêm các kết quả xét nghiệm bằng phương pháp thủcông. Do đó việc sử dụng các phương pháp kiểm tra delta thích hợp nhất trong phòng xét nghiệm có thể giảm thiểu khối lượng công việc và cải thiện tốc độ phát hiện lỗi [5],[6]. Hầu hết các phòng xét nghiệm đều dựa trên môt trong 4 phương pháp kiểm tra delta là: khác biêtt delta (delta difference), thay đổi phần trăm delta (delta percent change), khác biệt tỷ lệ (rate difference) và thay đổi phần trăm tỳ lể (rate percent change) cho mỗi xét nghiệm [7]. Môt thách thức lớn trong lựa chọn phương pháp kiểm tra delta là không có các tiêu chuẩn lựa chọn cụ thể được xác lập. Hơn nữa các đặc điểm lâm sàng của bểnh nhân có thể cần phải xem xét khi lựa chọn phương pháp kiểm tra delta thích hợp. Một số tình trạng bệnh nặng của bệnh nhân nổi trú sẽ có thể gây ra những thay đổi lớn về kết quả xét nghiệm, trong khi đó các bênh nhân ngoại trú thường có tình trạng ổn định hơon.

Theo hiểu biết của chúng tôi, ở Viêt Nam chưa có nhiều báo cáo về các phương pháp kiểm tra delta áp dụng trong phòng xét nghiệm. Để tìm hiểu về các phương pháp kiểm tra delta, lựa chọn phương pháp thích hợp cho từng xét nghiệm, đề tài này được thực hiện với mục tiêu: So sánh phân bố số liệu của khác biệt delta (delta difference) và thay đổi phần trăm delta (delta percent change) cho môt số xét nghiêm hoá sinh trên bệnh nhân nội trú và ngoại trú.

\section{II. ĐỐI TƯợNG VÀ PHƯƠNG PHÁP NGHIÊN CỨU}

1. Đối tượng nghiên cứu. Lựa chọn một số các xét nghiệm hoá sinh thường được chỉ định để theo dõi bệnh nhân: Natri, Kali, Clo, Canxi, Glucose, Urê, Creatinin, AST, ALT.

Thu thập kết quả các xét nghiệm trên trong vòng 6 tháng: các cặp kết quả trền cùng bệnh nhân, bệnh nhân ngoại trú và nội trú.

Các xét nghiệm được thực hiện trên bệnh nhân tại Bệnh viện đa khoa Thanh Nhàn, Hà Nội 
từ tháng 08/2020 đến tháng 02/2021

Đối tượng bệnh nhân: Bệnh nhân nội trú và ngoại trú, cả nam và nữ, độ tuổi chọn bệnh nhân từ trên 18 tuổi.

\section{Phương pháp}

-Thiết kế nghiên cứu trước sau, chọn mẫu có chủ đích, cõ̃ mầu thuận tiện

- Đặc điểm của đối tượng nghiên cứu như: tuổi, giới, kết quả xét nghiệm

- Tính toán và mô tả phân bố của kiểm tra delta bằng phần mền Excel:

+ Khác biệt delta $=$ Delta Difference (DD)= (Kết quả xét nghiệm hiện tại- Kết quả xét nghiệm trước đó)

+ Thay đổi phần trăm delta= Delta percent change (DPC) = (kết quả cao- kết quả thấp) /kết quả thấp x $100 \%$

3. Đạo đức nghiên cứu. Nghiên cứu chỉ thu thập số liệu sắn có của Phòng xét nghiệm không ảnh hưởng đến bệnh nhân (không lấy mẫu, không làm thêm xét nghiệm, không can thiệp...). Giữ bí mật về thông tin cá nhân của bệnh nhân tham gia nghiên cứu.

\section{KẾT QUẢ NGHIÊN CứU}

Nghiên cứu đã thu thập số liệu trên 555 bệnh nhân nội trú và 455 ngoại trú, trong đó có 512 bệnh nhân nam, 498 bệnh nhân nữ. Nam nhỏ nhất là 18 tuôi, lớn nhất là 99 tuổi, nữ nhỏ nhất 18 tuổi và lớn nhất 97 tuổi.

Bảng 1. Khác biệt delta trên bệnh nhân nội trú

\begin{tabular}{|c|c|c|c|c|c|c|c|c|}
\hline \multirow{2}{*}{$\begin{array}{l}\text { Xét nghiệm } \\
\text { (đđơn vị đio) }\end{array}$} & \multicolumn{7}{|c|}{ Khác biệt delta (DD) *Phân vị } & \multirow{2}{*}{$\begin{array}{l}\text { Số cặp } \\
\text { kết quả }\end{array}$} \\
\hline & 1 & 2.5 & 5 & 50 & 95 & 97.5 & 99 & \\
\hline Ürê (mmol/L) & -21.43 & -13.5 & -9.14 & -0.10 & 10.64 & 15.7 & 20.35 & 1215 \\
\hline Creatinin $(\mu \mathrm{mol} / \mathrm{L})$ & -25 & -159.6 & -84.3 & $-4 . \varepsilon$ & 67.97 & 101.48 & 154.76 & 904 \\
\hline Glucose $(\mathrm{mmol} / \mathrm{L})$ & -17.05 & -9.53 & -7.3 & -0.4 & 5.17 & 7.56 & 8.19 & 208 \\
\hline AST(U/L) & & -442.8 & -267.56 & -4.95 & 67.86 & 136.36 & 258.8 & 845 \\
\hline & & -4 & -195.1 & -2 & 79.85 & & 300.23 & \\
\hline Natri $(\mathrm{m}$ & -14.59 & -10.0 & -7.00 & 1.00 & 8.00 & 10.00 & 15.59 & 1441 \\
\hline Kali(mmol/L) & -2.35 & -1.60 & -1.30 & 0.00 & 1.20 & 1.50 & 1.85 & 1141 \\
\hline Clo (mmol/L) & -14.5 & -12.0 & -9.0 & 0.00 & 9.00 & 12.00 & 14.57 & 1141 \\
\hline Canxi (mmol/L) & -0.59 & -0.58 & -0.51 & 0.00 & 0.27 & 0.35 & 0.42 & 53 \\
\hline
\end{tabular}

*Khác biệt delta $=$ Delta Difference $(\mathrm{DD})=$ quả xét nghiệm hiện tại thấp hơn trước đó, có (Kết quả xét nghiệm hiện tại- Kết quả xét bệnh nhân kết quả xét nghiệm hiện tại cao hơn nghiệm trước đó) (đơn vị của DD chính là đơn vị trước đó. Các xét nghiệm điện giải đồ, urê có đo lường)

Nhận xét: Ở bệnh nhân nội trú, tất cả các xét nghiệm đều có DD ở cả hai phía của 0 (cả giá trị âm và dương), tức là có bệnh nhân có kết phân phối đối xứng. Các xét nghiệm Creatinin Glucose, AST, ALT, Canxi phối không đối xứng và có xu hướng lệch âm (tức là kết quả hiện tại có xu hướng thấp hơn kết quả xét nghiệm trước đó).

Bảng 2. Kêt quả khác biệt delta trên bệnh nhân ngoại trú

\begin{tabular}{|c|c|c|c|c|c|c|c|c|}
\hline \multirow{2}{*}{$\begin{array}{l}\text { Xét nghiệm } \\
\text { (đơn vị đo) }\end{array}$} & \multicolumn{7}{|c|}{ Khác biệt delta (DD)* Phân vị } & \multirow{2}{*}{$\begin{array}{l}\text { Số căp } \\
\text { kết quả }\end{array}$} \\
\hline & 1 & 2.5 & 5 & 50 & 95 & 97.5 & 99 & \\
\hline Urê $(\mathrm{mmol} / \mathrm{L})$ & -28.40 & -24.62 & -12.27 & 1.00 & 11.50 & 12.68 & 23.0 & 190 \\
\hline Creatinin $(\mu \mathrm{mol} / \mathrm{L})$ & -210.24 & -43.97 & -29.77 & 0.15 & 193.87 & 242.84 & 314.59 & 462 \\
\hline Glucose $(\mathrm{mmol} / \mathrm{L})$ & -6.12 & -4.10 & -1.91 & 0.89 & 2.30 & 3.52 & 7.76 & 1077 \\
\hline & -56 & -30.08 & -18.91 & -0.20 & 18.40 & 32.75 & 128.12 & 896 \\
\hline $\mathrm{AL}$ & -76.85 & -43.94 & -23.10 & -1.10 & 19.73 & 28.66 & 62.84 & 896 \\
\hline Natri $(1$ & -24.00 & -9.00 & -5.00 & -1.00 & 6.00 & 7.00 & 9.80 & 158 \\
\hline Kali (mmol/L) & -0.74 & -0.70 & -0.50 & 0.10 & 0.80 & 0.90 & 1.24 & 158 \\
\hline Clo ( & -13.00 & -10.05 & -5.00 & 0.00 & 5.05 & 7.00 & 9.23 & 158 \\
\hline Canxi $(\mathrm{mmol} / \mathrm{L})$ & -0.34 & -0.28 & -0.19 & -0.01 & 0.20 & 0.30 & 0.35 & 128 \\
\hline
\end{tabular}

*Khác biệt delta $=$ Delta Difference $(\mathrm{DD})=$ (Kết quả xét nghiệm hiện tại- Kết quả xét nghiệm trước đó) (đớn vị của DD chính là đơn vị đo lường)

Nhận xét: Ở bệnh nhân ngoại trú, tất cả các xét nghiệm đều có $D D$ ở cả hai phía của 0 (cả giá trị âm và dương), tức là có bệnh nhân có kết quả xét nghiệm hiện tại thấp hơn trước đó, có bệnh nhân kết quả xét nghiệm hiện tại cao hơn trước đó. Trong số các xét nghiệm thì canxi phân phối đối xứng, các xét nghiệm còn lại phân phối không đối xứng. 
Bảng 3. Kêt quả thay đổi phàn trăm delta trên bệnh nhân nội trú

\begin{tabular}{|c|c|c|c|c|c|c|c|}
\hline \multirow{2}{*}{$\begin{array}{l}\text { Xét nghiệm } \\
\text { (đđơn vị đơ) }\end{array}$} & \multicolumn{7}{|c|}{ Thay đổi phân trăm delta (\%) *Phân vị } \\
\hline & 1 & 2.5 & 5 & 50 & 95 & 97.5 & 99 \\
\hline Urê (mmol/L) & 0.00 & 0.84 & 2.24 & 32.14 & 195.66 & 276.69 & 432.82 \\
\hline Creatinin $(\mu \mathrm{mol} / \mathrm{L})$ & 0.13 & 0.55 & 1.23 & 14.68 & 92.46 & 138.4 & 212.99 \\
\hline Glucose $(\mathrm{mmol} / \mathrm{L})$ & 0.00 & 1.26 & 1.75 & 6.43 & 135.7 & 228.5 & 316.7 \\
\hline AST(U/L) & 0.55 & 1.55 & 3.37 & 31.37 & 78.77 & 87.31 & 92.42 \\
\hline & 0.78 & 1.70 & 3.12 & 30.50 & 74.64 & 85.96 & 91.72 \\
\hline Natri(m & 0.00 & 0.00 & 0.00 & 1.96 & 7.80 & 10.29 & 16.10 \\
\hline Kali (mmol/L) & 0.00 & 0.00 & 0.00 & 11.76 & 51.72 & 62.96 & 87.5 \\
\hline Chlorid(mmol/L) & 0.00 & 0.00 & 0.00 & 2.97 & 12.64 & 15.64 & 18.94 \\
\hline Canxi (mmol/L) & 0.00 & 0.00 & 0.00 & 2.49 & 11.72 & 18.1 & 21.76 \\
\hline
\end{tabular}

*Thay đối phần trăm delta $=$ Delta percent change $=$ (kết quả cao- kết quả thấp) /kết quả thấp x100\% (đơn vị đo là \%).

Nhận xét: Phần lớn các xét nghiệm có phân vị thứ 1 là $0 \%$ (6/9 xét nghiệm) và xấp xỉ với $0 \%$. Điều này phù hợp với trung vị các kết quả xét nghiệm hiện tại xấp xỉ với trung vị kết quả xét nghiệm trước đó, do vậy thay đổi phần trăm delta xấp xỉ với 0 . Phân vị thứ 95 của của các xét nghiệm Natri, Clo, Canxi $<20 \%$, các xét nghiệm Kali, $\mathrm{AST}$, $\mathrm{ALT}$, Urê $>50 \%$, các xét nghiệm creatinine và̀ glucose đều $>100 \%$.

Bảng 4. Kêt quả thay đổi phần trăm delta trên bệnh nhân ngoại trú

\begin{tabular}{|c|c|c|c|c|c|c|c|}
\hline \multirow{2}{*}{$\begin{array}{c}\text { Xét nghiệm } \\
\text { (đơn vị đo) }\end{array}$} & \multicolumn{7}{|c|}{ Thay đối phần trăm delta (\%) *Phân vị } \\
\hline & 1 & 2.5 & 5 & 50 & 95 & 97.5 & 99 \\
\hline Urê $(\mathrm{mmol} / \mathrm{L})$ & 1.0 & 1.19 & 2.10 & 21.70 & 98.18 & 222.94 & 522 \\
\hline Creatinin(mmol/L) & 0.18 & 0.37 & 0.76 & 7.34 & 35.33 & 44.19 & 57.21 \\
\hline Glucose(mmol/L) & 0.00 & 1.71 & 4.53 & 11.68 & 54.22 & 89.60 & 127.57 \\
\hline AST(U/L) & 0.36 & 0.80 & 1.61 & 16.98 & 103.50 & 132.54 & 217.64 \\
\hline ALT(UL) & 0.62 & 1.36 & 2.27 & 24.77 & 127.49 & 185.28 & 266.46 \\
\hline Natri(mmol/L) & 0.00 & 0.00 & 0.00 & 1.45 & 5.55 & 11.47 & 23.69 \\
\hline Kali $(\mathrm{mmol} / \mathrm{L})$ & 0.00 & 0.00 & 0.00 & 5.88 & 21.14 & 24.30 & 34.78 \\
\hline Chlorid(mmol/L) & 0.00 & 0.00 & 0.00 & 1.98 & 8.65 & 12.40 & 14.94 \\
\hline Calcium(mmol/L) & 0.00 & 0.41 & 0.42 & 2.59 & 13.36 & 15.80 & 18.62 \\
\hline
\end{tabular}

*Thay đổi phần trăm delta $=$ Delta percent change $=$ (kết quả cao- kết quả thấp)/kết quả thấp $\mathrm{x} 100 \%$

Nhận xét: Ngoại trừ xét nghiệm urê phân vị 1 là $1.0(\%)$ còn các xét nghiệm khác đều nhỏ hơn 1 và xấp xỉ $0(\%)$. Điêu này phù hợp với trung vị các kết quả xét nghiệm hiện tại xấp xỉ với trung vị kết quả xét nghiệm trước đó, do vậy thay đổi phần trăm delta xấp xỉ với 0 . Phân vị thứ 95 của của các xét nghiệm Natri, Clo, Canxi $<20 \%$, các xét nghiệm Kali, creatinin < $50 \%$, Glucose, ure $>50 \%$, các xét nghiệm AST, ALT > 100\%.

\section{BÀN LUÂ̂N}

Các phương pháp kiểm tra delta đảm bảo phát hiện các sai sót trước xét nghiệm, sai số ngẫu nhiên không thể phát hiện được bằng các phương pháp kiểm tra chất lượng xét nghiệm thường dùng, do vậy làm cải thiện độ tin cậy của kết quả xét nghiệm. Trong nghiên cứu này, chúng tôi mô tả phân phối của cả 2 phương pháp kiểm tra delta thường được sử dụng: khác biệt delta (delta difference), thay đổi phần trăm delta (delta percent change). Các xét nghiệm

nghiên cứu bao gồm: urê, creatinin, glucose, ASI, ALT, điện giải đồ (natri, kali, clo) và canxi. Trong nghiên cứu này, phân bố kiểm tra delta theo cả 2 phương pháp được mô tả và được phân chia theo 2 nhóm bệnh nhân nội trú và ngoại trú. Các bệnh nhân nội trú, đặc biệt bệnh nhân nặng và có can thiệp điều trị tích cực, thường có sự thay đổi kết quả xét nghiệm nhiều hơn; do vậy việc sử dụng các ngưỡng cảnh báo delta khác với bệnh nhân ngoại trú (thường trong tình trạng ổn định hơn) là điều hợp lý [7],[8]. Phân bố khác biệt delta (DD) ở các phân vị $1,2.5,5,95,97.5$ và 99 trên bệnh nhân nội trú của xét nghiệm AST, ALT là lớn hơn rất nhiều so với khác biệt delta này trên bệnh nhân ngoại trú (bảng 1 và bảng 2). Điều này cho thấy khi tế bào gan bị tổn thương hay hủy hoại do nhiều nguyên nhân khác nhau thì thường là lý do khiến bệnh nhân phải nhập viện điều trị nội trú. Với các xét nghiệm kali và canxi, khác biệt delta ở 
các phân vị 1 1, 2.5 , 5, 95, 97.5 và 99 trên bênh nhân nội trú cũng có xu hướng lớn hơn bệnh nhân ngoại trú. Điều này cũng dế lý giải bởi đây là các ion mà sự hằng định nội môi của chúng vô cùng quan trọng với sự sống của cơ thể, do vậy các bệnh nhân ngoại trú sự biến động của các ion này sẽ ít hơn. Với xét nghiệm urê và creatinin, phân bố khác biệt delta trên bệnh nhân nôi và ngoai trú có xu hướng tương tư nhau (bảng 1 và 2), điều này có thể giải thích bằng có nhóm bệnh nhân thận mạn chạy thận nhân tao sẽ không nằm điều trị nội trú. Ớ bênh nhân nội trú và ngoaii trú, tất cả các xét nghiệm đều có khác biệt delta (DD) ở cả hai phía của 0 (cả giá trị âm và dương), tức là có bệnh nhân có kết quả xét nghiệm hiện tại thấp hơn trước đó, có bệnh nhân kểt quả xét nghiệm hiên tại cao hơn trước đó. Với bệnh nhân nội trú, các xét nghiệm điện giải đồ, urê có phân phối đối xứng. Các xét nghiệm Creatinin, Glucose, AST, ALT, Canxi phối khồng đối xứng và có xu hướng lệch âm (tức là kết quả hiện tại có xu hướng thấp hơn kết quả xét nghiệm trước đó). Với bệnh nhân ngoại trú, trong số các xét nghiệm thì canxi phân phối đối xứng, các xét nghiệm còn lại phân phối không đối xứng. Từ phân bố kết quả khác biệt delta của 9 xét nghiệm cho thây việc sử dụng các ngưỡng cảnh báo delta theo phương pháp khác biêtt delta sẽ khác nhau cho một số xét nghiệm trên 2 đối tượng bệnh nhân nội trú và ngoại trú vì biến đổi sinh lý bệnh của 2 nhóm bênh nhân này không giống nhaú. Việc sử dụng chung ngưỡng cảnh báo có thể dẫn tới nhiều cảnh báo dương tính giả hoặc âm tính giả [8].

Một phương pháp tiếp cận nữa trong kiểm tra delta là tính thay đổi phần trăm delta (DPC). Trong nghiên cứu này công thức thay đổi phần trăm delta $=$ Delta percent change $=$ (kết quả cao- kết quả thấp) /kết quả thấp x $100 \%$ nên các kết quả thu được luôn mang giá trị dương. Với bệnh nhân nội trú, phân vị thứ 95 của của các xét nghiệm Natri, Clo, Canxi $<20 \%$, các xét nghiệm Kali, AST, ALT, ure > 50\%, các xét nghiệm creatinine và glucose đều $>100 \%$ (bảng 3). Với bệnh nhân ngoại trú, phân vị thứ 95 của của các xét nghiệm Natri, Clo, Canxi $<20 \%$, các xét nghiệm Kali, creatinin < $50 \%$, Glucose, ure > $50 \%$, các xét nghiêm AST, ALT > 100\% (bảng 4). Khi so sánh với bệnh nhân nội trú, phân vị thứ $50,95,97.5$ và 99 của thay đổi phần trăm delta của các xét nghiệm urê, creatinin, glucose, canxi trên bệnh nhân ngoại trú nhỏ hơn (bảng 3 và 4), trong khi AST, ALT, Natri, Kali, Clo lại có xu hướng ngược lại. Điều này có thể lý giải là các xét nghiệm đánh giá hủy hoại tế bào gan (ALT, AST) và điện giải đồ khi có sự thay đổi nhiều sẽ xuất hiện các triệu chứng lâm sàng bất thường, là lý do khiến bểnh nhân ngoại trú tái khám. Nếu như so sánh khác biệt delta (DD) ở của AST và ALT ở bệnh nhân nội trú lớn hơn ngoại trú (bảng 1 và 2) thì so sánh thay đổi phần trăm delta (DPC) của hai xét nghiêm này ở bênh nhân ngoại trú lại lớn hơn nội trú (bảng 3 và 4). Điều này cũng hoàn toàn có thể lý giải được là trên bệnh nhân nội trú khoảng thời gian giữa 2 lần xét nghiệm là ngắn hơn rất nhiêu, tình trạng bệnh nhân nội trú có tăng hoạt độ AST, ALT thường nặng, nên nếu xem xét mức nồng độ thì sẽ thấy tăng cao và sự biến thiên giữa hai lần xét nghiêm cũng chêch lêch lớn (tức là khác biệt delta lớn). Tuy nhiên, khi tính thay đổi phần trăm delta thì sự chênh lệch này được chuyển về phần trăm ((kết quả cao- kết quả thấp)x100\%/ kết quả thấp )) nên sự thay đổi của AST và ALT của bệnh nhân ngoại trú lại lớn hơn ở bệnh nhân nội trú (bảng 3 và 4). Kết quả này một lần nữa cho thấy việc phân chia bệnh nhân thành nhóm nội trú và ngoại trú là thích hợp để xác định các ngưỡng kiểm tra delta phù hợp cho mỗi đối tượng này. Việc sử dụng các phương pháp kiểm tra khác biệt delta hoặc thay đổi phần trăm delta phụ thuộc vào độ lớn của các giá trị xét nghiệm. Khác biệt Delta (DD) dựa trên sự khác biệt có xu hướng hữu ích ở phạm vi giá trị xét nghiệm thấp hơn hoặc xung quanh các giá trị quan trọng đối với các quyết định lâm sàng. Trái lại, các phương pháp thay đổi phần trăm delta (DPC) thường là hữu ích cho các giá trị xét nghiệm cao hơn [9].

\section{KẾT LUÂNN}

Phân bố khác biệt delta (DD) ở các mức phân vị trên bệnh nhân nội trú của xét nghiệm Glucose, AST, ALT, Natri, Kali, Clo, Canxi lớn hơn so với trên bệnh nhân ngoại trú. Với xét nghiệm urê và creatinin, phân bố khác biệt delta trên bệnh nhân nội và ngoại trú có xu hướng tương tự nhau. Khi so sánh với bệnh nhân nội trú, phân vị thứ $50,95,97.5$ và 99 của thay đổi phần trăm delta (DPC) của các xét nghiệm urê, creatinin, glucose, canxi trên bệnh nhẩn ngoại trú nhỏ hơn; trong khi AST, ALT', Natri, Kali, Clo lại có xu hướng ngược lại.

\section{TÀI LIẸU THAM KHẢO}

1. Bonini, P., et al., Errors in laboratory medicine. Clin Chem, 2002. 48(5): p. 691-8.

2. Snydman, L.K., et al., Voluntary electronic reporting of laboratory errors: an analysis of 37,532 laboratory event reports from 30 health care organizations. Am J Med Qual, 2012. 27(2): 
p. $147-53$.

3. Kazmierczak, S.C., Laboratory quality control: using patient data to assess analytical performance. Clin Chem Lab Med, 2003. 41(5): p. 617-27.

4. Straseski, J.A. and F.G. Strathmann, Patient data algorithms. Clin Lab Med, 2013. 33(1): p. 147-60.

5. Nosanchuk, J.S. and A.W. Gottmann, CUMS and delta checks. A systematic approach to quality control. Am J Clin Pathol, 1974. 62(5): p. 707-12.

6. Wheeler, L.A. and L.B. Sheiner, A clinical evaluation of various delta check methods. Clin Chem, 1981. 27(1): p. 5-9.
7. Park S, Kim S-Y, Lee W, Chun S, Min W-K. New Decision Criteria for Selecting Delta Check Methods Based on the Ratio of the Delta Difference to the Width of the Reference Range Can Be Generally Applicable for Each Clinical Chemistry Test Item Annals of laboratory medicine. 2012; 32:345-354.

8. Kim, J.W., J.Q. Kim, and S.I. Kim, Differential application of rate and delta check on selected clinical chemistry tests. J Korean Med Sci, 1990. 5(4): p. 189-95.

9. Lacher, D.A. and D.P. Connelly, Rate and delta checks compared for selected chemistry tests. Clin Chem, 1988. 34(10): p. 1966-70.

\title{
LÂM SÀNG, CÂN LÂM SÀNG BÊ̂NH NHÂN COVID-19 VÀ SốT RÉT TẠI BỆNH VIỆN BỆNH NHIỆT ĐỚI TRUNG ƯƠNG
}

\author{
Thân Mạnh Hùng1, Nguyễn Đức Minh', Lê Văn Nam²
}

\section{TÓM TẮT}

Mục tiêu: Mô tả đặc điểm lâm sàng, cận lâm sàng của bểnh nhân COVID-19 và bệnh nhân sốt rét trong vụ dịch COVID-19 năm 2020. Đối tượng và phương pháp: Mổ tả cắt ngang 71 bệnh nhân, trong đó 60 bệnh nhân COVID-19 và 11 bệnh nhân sốt rét điều trị tại Bệnh viện Bệnh Nhiệt đới trung ương, thu thập về các biểu hiện lâm sàng, cận lâm sàng và diễn biến của bệnh.Kết quả: Sốt hay gặp ở nhóm sốt rét $(90,1 \%)$, cao hơn nhóm COVID-19 (45\%). Ho gặp chủ yếu ở nhóm BN COVID-19 (75\%). Thời gian ủ bệnh trung bình của bệnh nhân COVID-19 là 6,53 \pm 4,07 ngày. Thời gian thanh thải virus: $8,22 \pm 4,83$ ngày. Thời gian sach KST sốt rét trong máu là 4,18 $\pm 2,09$ ngày. Nhóm sốt rét D-dimer tăng cao (IQR: $2829 \mathrm{ng} / \mathrm{ml}$ so với 733 $\mathrm{ng} / \mathrm{ml})$, với $\mathrm{p}=0,002$. PCT ở bệnh nhân sốt rét tăng cao hơn bênh nhân COVID-19 (IQR: $1,715 \mathrm{ng} / \mathrm{ml}$ so với $0,028 \mathrm{ng} / \mathrm{ml}$ ) với $\mathrm{p}=0,02$. 75\% bệnh nhân có tổn thương phối trên phim CT ngực, chủ yếu tổn thương 2 bên (80\%). Kết luận:Sốt là triệu chứng chung của sốt rét và COVID-19, không nên bỏ qua bệnh sốt rét trong các vụ dịch COVID-19 nếu bệnh nhân có yếu tố dịch tễ.

Tư khoá: SARS-CoV2, COVID-19, Sốt rét

\section{SUMMARY}

CLINICAL MANIFESTATION AND LABORATORY RESULTS AMONG COVID-19 AND MALARIA PATIENTS IN NATIONAL

HOSPITAL FOR TROPICAL DISEASES

Objectives: This study aims to describe the clinical manifestation and laboratory results among

\footnotetext{
${ }^{1}$ Bệnh viện Bệnh Nhiệt đới Trung ương

²Bệnh viện Quân Y 103

Chịu trách nhiệm chính: Thân Mạnh Hùng

Email: hungykhoa@gmail.com

Ngày nhận bài: 24.6.2021

Ngày phản biện khoa học: 18.8.2021

Ngày duyệt bài: 27.8.2021
}

COVID-19 and malaria patients in 2020.Participants and Methods: We conducted a cross-sectional study on 71 patients include 60 confirmation of SARS-CoV-2 using RT-PCR method and 11 malaria patients at National Hospital for Tropical Diseases. We collected information about clinical and subclinical characteristics by direct interview or extract from medical records. Results: The most common symptoms of malaria patients at admission were fever $(90.1 \%)$, in COVID-19 patients were $45 \%$, dry cough were common symptoms of COVID-19 patients (75\%) and The mean incubation period was 6.53 days. Duration of viral shedding was $8.22 \pm 4.83$ days. Clearance of parasitic malaria was $4.18 \pm 2.09$ days. D-Dimer in malaria patients increased (IQR: 2829 $\mathrm{ng} / \mathrm{mL}$ compared to $733 \mathrm{ng} / \mathrm{ml}$ ), with $\mathrm{p}=0.002$.PCT in malaria patients increased higher than COVID-19 patients (IQR: $1,715 \mathrm{ng} / \mathrm{mL}$ compared to $0.028 \mathrm{ng} / \mathrm{ml}$ ) with $\mathrm{p}=0.02$. On chest radiographs, we found lung damage in about $75 \%$ of patients. The bilateral lung damage was accounted $80 \%$, and mostly seen in the middle and the bottom of the lung. Conclusion: Fever is a common symptom of malaria and COVID19 , should not ignore malaria in COVID-19 pandemic if the patient has epidemiological elements.

Keywords; SARS-CoV-2, COVID-19, malaria

\section{I. ĐẶT VẤN ĐỀ}

Hội chứng suy hô hấp cấp do Coronavirus 2 (SARS-CoV2) lần đầu tiên được phát hiện vào cuối tháng 12/2019 tại tỉnh Vũ Hán - Trung Quốc. Tính đến ngày $06 / 06 / 2021$ trên toàn Thế giới ghi nhận tại 213 Quốc gia với 173,729,856 trường hợp nhiễm, tử vong 3,736,525 trường hợp chiếm tỷ lệ 2,15\%[1]. SARS-CoV2 là một coronavirus mới, lần đầu tiên được phát hiện gầy bệnh trên người. Bệnh lây từ người sang người qua giọt bắn đường hô hấp khi tiếp xúc gần. Bệnh gặp ở mọi lứa tuổi, với thời gian ủ bệnh trung bình 3 ngày với các triệu chứng chủ yếu là ho, sốt. Bệnh cảnh chủ yếu là viêm đường hô 